\title{
Políticas e Poéticas do Audiovisual na contemporaneidade: por uma antropologia do cinema - Apresentação
}

\author{
Eliska Altmann ${ }^{1}$ (org.) \\ Universidade Federal Rural do Rio de Janeiro \\ Debora Breder ${ }^{2}$ (org.) \\ Universidade Cândido Mendes \\ Luis Felipe Kojima Hirano ${ }^{3}$ (org.) \\ Universidade Federal de Goiás \\ Marcos Aurélio da Silva ${ }^{4}$ (org.) \\ Universidade Federal de Mato Grosso
}

\footnotetext{
${ }^{1}$ Professora adjunta da Universidade Federal Rural do Rio de Janeiro, no Departamento de Ciências Sociais e no Programa de Pós-Graduação em Ciências Sociais (PPGCS). Integrante do Grupo de Análises de Políticas e Poéticas Audiovisuais (GRAPPA).

${ }^{2}$ Doutora em Antropologia pela Universidade Federal Fluminense, com estágio doutoral na École des Hautes Études en Sciences Sociales. Formada em Cinema pela Escuela Internacional de Cine, Televisión y Video de San António de Los Baños, Cuba. Integrante do GRAPPA.

3 Professor da Faculdade de Ciências Sociais e do Programa de Pós-Graduação em Antropologia Social da Universidade Federal de Goiás. Integrante do GRAPPA.

4 Professor permanente do PPGAS/UFMT. Pesquisador do INCT Brasil Plural. Bolsista PNPD/Capes. Integrante do GRAPPA.
} 
Se esta apresentação tivesse título, ele poderia ser "Entre o passado e o futuro". Menos que um plágio à obra de Hannah Arendt, nosso intento seria retomar uma pequena historiografia (a compor uma espécie de "mais do mesmo"), de modo a gerar uma autorreflexão - do papel deste dossiê e do GRAPPA, no tempo presente, e suas futuras intenções. Assim, valeria resgatarmos a questão sobre o que era a antropologia à época do nascimento do cinema. Diríamos se tratar de uma disciplina a compor reflexões teóricas sobre sociedades e suas diversidades, cujo material colhido (por viajantes) agregava elementos físicos (biológicos), coerentes a certas perspectivas deterministas do período. Naquele momento, cinema e antropologia configuravam ferramentas da era industrial expansionista, quando o mundo ocidental e seu espírito científico eram marcados pela ideia de progresso e pela constituição do conhecimento como "verdade" irrefutável. Ambos tratavam de explorar "novos mundos”, assegurando sua apreensão, seu registro e colonização. O ocidente, deste modo, carregava o "fardo do homem branco", civilizando e retratando o "bom selvagem".

Sabe-se que, em suas primeiras experiências, o cinema (com suas várias transformações mecânicas, que compreenderam aparelhos como o cronofotógrafo, o kinetoscópio, entre outros), foi usado por cientistas (positivistas) como Étienne-Jules Marey e Félix Regnault que, anti-ilusionistas, eram curiosos - exclusivamente - pela decomposição do movimento. Aparato fundamental para o desenvolvimento de ciências "duras", o cinema levantou questões daqueles domínios para a nascida antropologia, referentes às imagens, contínuas e descontínuas, do "outro".

Concomitante ao surgimento do trabalho de campo, mais precisamente com Franz Boas, foram criados o cinematógrafo, o fotograma e a película cinematográfica, e a câmera, no início do século $\mathrm{XX}$, já era vista como um efetivo instrumento de relação entre "filmante" e filmado, como o mais eficiente aparelho de "registro da realidade". A favor de empreendimentos colonizadores, cinema e ciência, de modo geral, instrumentalizavam narrativas, dando voz aos antropólogos. Tal postura de conferir autoridade ao "autor" das imagens e dos "objetos" filmados começaria a cair por terra pouco mais de meio século depois, quando Jean Rouch instaurou o método da "antropologia compartilhada" e questionou o pressuposto de verdade científica (ou cinematográfica). Nesse momento, é colocada em xeque certa inocência epistemológica de correntes da antropologia, crentes na existência de narrativas objetivas, uma vez que interpretações subjetivas se tornam passíveis de compor diferentes vozes e visões.

A partir daqui, nos colocamos. E todo esse preâmbulo nos serve para discutir o estatuto da relação entre cinema e antropologia nos dias atuais, assim como suas possibilidades outras, embora afins. Tomemos, então, a referência do antropólogo Marc Henri Piault, para quem, no início do século XXI, 


\begin{abstract}
se efetuar a não ser a partir de elementos visuais que teriam suas qualidades de restituição asseguradas, de tal forma que pudesse discorrer sobre elas tal como se faria a respeito da realidade no seu próprio campo de existência. Esta representação, tão forte, tem por corolário uma desconfiança constante em relação a tudo que poderia parecer uma mise-en-scène, uma reconstituição, ou pior ainda, uma ordem ficcional. (PIAULT, 2001: 151-52)
\end{abstract}

Não obstante o reconhecimento tardio e receoso do cinema pela antropologia, consideramos ser possível sublinhar ao menos três aspectos em que se deram (e se dão) suas interlocuções. Em primeiro lugar, destacamos o emprego de equipamentos e linguagens cinematográficas no registro de alteridades (e suas reflexões), por meio de variados métodos, formas de aproximação e estéticas, que vão de Robert Flaherty a Trinh T. Minh-ha, passando por Rouch, David MacDougall, entre tantos outros. Um segundo modo de interlocução seria o uso do cinema como objeto de pesquisa e como meio de acessar determinadas culturas. Exemplos desta prática podem ser conferidos em experiências de Ruth Benedict, Margareth Mead e Gregory Bateson, que realizaram análise fílmica e métodos de recepção para compreender noções de honra, lealdade, filiação, entre outros aspectos de culturas orientais como as melanésias, a balinesa, a japonesa, as australianas, as soviéticas, entre outras. Por fim, a partir da década de 1980, surgem importantes representantes da corrente antropológica denominada pósmoderna, como James Clifford e George Marcus, que problematizaram entendimentos canônicos da prática etnográfica, apontando à crise da identidade pessoal do antropólogo.

Como explica José Reginaldo Gonçalves,

\begin{abstract}
ao desconstruir a noção clássica da autoria e/ou da autoridade etnográfica, Clifford faz objeção a certo fundamentalismo que tem caracterizado concepções etnográficas de cultura, e, ao fazê-lo, questiona a própria epistemologia do mundo moderno que busca obsessivamente fundamentos de natureza objetiva ou subjetiva. (GONÇALVES, 1998: 13)
\end{abstract}

Entendemos que, ao questionar a autoria ou a autoridade do eu etnográfico, Clifford propõe o que concebe por polifonia dialógica. Desta maneira, o entrecruzamento por ele proposto acaba por des-subjetivar o autor, antes coerente e centralizado, prevendo outra forma de subjetivação. Tal desconstrução representativa implica uma re-subjetivação da outridade 5 .

Pensada em âmbito cinematográfico, esta concepção passa a problematizar o estatuto verídico e objetivo da imagem, na medida em que a intersubjetividade autoral permite aos sujeitos se revelarem ou fabularem, borrando fronteiras preestabelecidas entre cinema e antropologia, como o próprio ideal de verdade, do outro como alteridade ou homogeneidade, e de determinadas regras de linguagem. Com isso, evidenciam-se novos usos de conceitos e linguagens cinematográficas como fontes para a escrita etnográfica, conforme desenvolvido por George Marcus, no uso do termo mise-en-scène etnográfica, e Michael Taussig, ao lançar mão da ideia de montagem eisensteiniana, via Walter Benjamin.

Claro está que as três dimensões dialogam entre si e não se circunscrevem a períodos históricos necessariamente estáticos e cronológicos. Tal tríade parece constituir elementos basilares que vêm possibilitando o diálogo entre antropologia e cinema, na institucionalização da subdisciplina antropologia

5 Para mais detalhes, ver ALTMANN, 2009: 57-79. 
visual. Tanto que ela (a tríade) pode ser identificada na fundamentação de estudos que articulam imagens e ciências sociais no Brasil. Dentre eles, notamos a publicação contínua de dissertações, teses e livros na área, o estabelecimento de núcleos de pesquisa ${ }^{6}$ certificados pelo $\mathrm{CNPq}$, e o reconhecimento de Grupos de Trabalho em espaços consolidados, como a Reunião Brasileira de Antropologia e a ANPOCS. Notamos igualmente o importante papel de revistas especializadas no tema, como os Cadernos de antropologia e imagem, da UERJ, e ressaltamos, ainda, no âmbito das reuniões e associações, a criação do Prêmio Pierre Verger, em 1996, para filmes e ensaios fotográficos, na ABA, e a Sessão de Vídeos instituída a partir do $15^{\circ}$ Encontro anual da ANPOCS, em 1991. Com isso, afirmamos ser inegável o crescimento do campo nas últimas décadas7.

Como fruto das diversas tendências, em 2012, surge o GRAPPA - Grupo de Análises de Políticas e Poéticas Audiovisuais ${ }^{8}$ - visando a inserção em um debate amplo e promissor, cujo enfoque, diferentemente, abrange a análise antropológica do cinema, entendido em sentido lato a englobar produção, circulação e recepção, entre outras conexões possíveis de análise. Ao congregar pesquisadores de diversos perfis e universidades, o GRAPPA se propõe a perscrutar estatutos cinematográficos, bem como implicações epistemológicas de construção e interpretação de mundos sociais. Com isso, discutimos abordagens teórico-metodológicas de investigações que lançam mão de filmes documentais, ficcionais, experimentais, entre outros estilos e não convenções como instrumentos, objetos e/ou métodos de pesquisa. Assim, tratamos de debater fluxos e contrafluxos de narrativas audiovisuais contemporâneas em suas várias dimensões, com olhar em:

1) modos como aparatos audiovisuais têm sido utilizados em investigações;

2) articulações entre cinema, narrativas, memórias e subjetividades;

3) representações e interpretações de cinematografias sobre temas como: relações natureza/cultura, centro/periferia, corpo, gênero, sexualidade, classe, raça/etnia, identidade, etc.;

4) condições sociais de produção, circulação e recepção de obras em diferentes formatos e gêneros.

$\mathrm{Na}$ busca por avaliar desafios, dilemas e potencialidades de novas representações (geradas, inclusive, por novas ferramentas e mídias), nos últimos anos, o grupo tem participado de eventos científicos, como simpósios, congressos, mesas redondas ${ }^{9}$, de forma a aprofundar e discutir conexões

\footnotetext{
${ }^{6}$ Destacamos, por exemplo: Lisa (Laboratório de Imagem e Som em Antropologia/USP), INARRA (Grupo de Pesquisa Imagens, Narrativas e Prática Culturais/UERJ), NAI (Núcleo de Antropologia e Imagem/UERJ), NAVISUAL (Núcleo de Antropologia Visual/UFRGS), NAVI (Núcleo de Antropologia Visual e Estudos da Imagem/UFSC), NEXTimagem (Núcleo de Experimentações em Etnografia e Imagem/UFRJ).

7 Neste contexto, verifica-se uma especialização nos debates e a criação de subáreas que circunscrevem discussões referentes às artes ocidentais e não ocidentais, à fotografia, à patrimonialização, à produção de filmes etnográficos, às diferentes formas de recepção, às representações de gênero e étnico-raciais expressas em aparatos artísticos, entre outros segmentos.

8 O GRAPPA conta com pesquisadores das seguintes universidades e instituições: UFRRJ, UFS, UFMT, UERJ, UCM, UFG, UFRJ, UFMG, PUC-MG, FURB e ENCE/IBGE.

9 Desde 2012, o grupo tem se reunido em importantes eventos acadêmicos, como a Reunião Brasileira de Antropologia (RBA), a Reunião de Antropologia do Mercosul (RAM), a Reunião Equatorial de Antropologia (REA), o Seminário Internacional Fazendo Gênero, o Congresso Latino-americano de Antropologia (ALA), o Encontro Anual da Associação Nacional de Pós-Graduação e Pesquisa em Ciências Sociais (ANPOCS), o Encontro de Antropologia Visual da América
} 
múltiplas e singulares entre antropologia e cinema, a partir da subárea por nós intitulada "antropologia do cinema".

Os três anos de experiência nos permitiram identificar a produção sobre cinema e audiovisual em quatro traços consistentes de diálogo:

1) estudos que se debruçam sobre o cinema para analisar representações e imaginários sociais, seja de períodos históricos, ou de categorias sociais, como gênero, sexualidade, classe e raça/etnia;

2) estudos que analisam a produção audiovisual por meio da perspectiva da sociologia da cultura, examinando a formação do campo cultural, trajetórias e gerações;

3) pesquisas que compreendem formas audiovisuais como mediadoras de diferentes relações sociais;

4) investigações sobre o uso de imagens como mecanismos para analisar diferentes fenômenos sociais.

Nesse contexto, o presente dossiê Políticas e Poéticas do Audiovisual na contemporaneidade: por uma antropologia do cinema, organizado pelo GRAPPA em parceria com o PPGAS/UFMT, reúne trabalhos apresentados em encontros, englobando os mais diversos temas, como os festivais de cinema da diversidade sexual; representações de gênero no mercado cinematográfico; gênero e incesto; a produção cinematográfica de coletivos feministas, queers ou LGBTs em festivais de cinema no Brasil e nos Estados Unidos; conexões entre segregação racial e narrativa clássica hollywoodiana; relações entre cinema e saúde; trajetórias de movimentos artísticos; estratégias para analisar documentários "anamorfóticos" e "ontológicos"; considerações estéticas; crítica e distinção; "cinema de mulheres"; política; novas mídias.

Os artigos aqui reunidos abordam o cinema como veículo expressivo a revelar antigas e novas alteridades, utopias e distopias contemporâneas. Além disso, eles tratam de indagar sobre as contribuições das ciências sociais em relação à produção audiovisual e, inversamente, de quais formas a produção audiovisual, em seus mais diferentes formatos, apresentam questões para as ciências sociais, em suas diferentes linhas. Com os textos, podemos levantar perguntas como: De que maneira a análise de filmes contribui para pensarmos a construção de imaginários sociais sobre gênero, sexualidade, geração, etnia/raça e classe? Ou ainda, como etnografias de festivais de cinema $e$ análises quantitativas trazem novas dimensões para um exame do campo cultural?

Em que pese a diversidade de abordagens, é possível encontrar três eixos aqui subdivididos em: Cinema \& Teoria Antropológica; Cinema \& Gênero; e Cinema \& Pós-colonialidade. Acreditamos que tais tendências, longe de sintetizarem conexões entre antropologia e audiovisual, sinalizam novos modos de configuração social e suas expressões. Verificamos, deste modo, que o cinema (em sentido amplo) tem sido um interlocutor essencial para tecer relações entre teorias e para pensar interseccionalidades das várias dimensões que constroem sujeitos contemporâneos. 
Com isso, convidamos leitores e leitoras a desfrutarem dos artigos aqui reunidos, vislumbrando outras conexões entre cinema(s) e ciências sociais. Tais conexões postulam uma amplitude e uma diversidade que extrapolam limites da antropologia visual, estabelecendo, ao mesmo tempo, diálogos com a mesma. Assim, com esta primeira organização, buscamos semear frutos sob o solo fértil e interdisciplinar da antropologia do cinema.

Por fim, gostaríamos de lembrar que, além dos autores desta apresentação, também participaram do dossiê, atuando como pareceristas, os seguintes membros do Grupo de Análises de Políticas e Poéticas Audiovisuais (GRAPPA): Luiz Gustavo Pereira de Souza Correia, da Universidade Federal de Sergipe; e Ana Paula Pereira da Gama Alves Ribeiro, da Universidade Estadual do Rio de Janeiro. Paula Alves, Paloma Coelho e Juliano Gonçalves da Silva também integrantes do GRAPPA participam com artigos nesta coletânea. O GRAPPA e o PPGAS/UFMT agradecem a todos os outros pareceristas que contribuíram para a edição deste dossiê, assim como os autores de artigos que, mesmo não sendo membros do GRAPPA, se dispuseram a dialogar com o grupo através de suas contribuições.

\section{Referências}

ALTMANN, Eliska. Verdade, tempo e autoria: três categorias para pensar o filme etnográfico. Revista Anthropológicas, 20. Porto Alegre, UFRGS, 2009.

GONÇALVES, José Reginaldo. A Experiência Etnográfica: Antropologia e Literatura no Século XX, James Clifford. 1. ed. Rio de Janeiro, Editora da UFRJ, v. $1,1998$.

PIAULT, Marc Henri. “Real e ficção: onde está o problema?” In: KOURY, M. G. P. (org.). Imagem e memória: estudos em antropologia visual. Rio de Janeiro, Garamond, 2001. 